\title{
Separation Performance of Sodium Alginate/Poly(Vinyl Pyrrolidone) Membranes for Aqueous/Dimethylformamide Mixtures by Vapor Permeation and Vapor Permeation with Temperature Difference Methods
}

\author{
Ebru Kondolot Solak ${ }^{1}$, Oya Şanlı ${ }^{2^{*}}$ \\ ${ }^{1}$ Department of Cemistry and Chemical Processing Technology, Atatürk Vocational High School, \\ Gazi University, Teknikokullar, Ankara, Turkey \\ ${ }^{2}$ Faculty of Science, Department of Chemistry, Gazi University, Teknikokullar, Ankara, Turkey \\ E-mail:"osanli@gazi.edu.tr \\ Recieved July 18, 2011; revised September 7, 2011; accepted September 19, 2011
}

\begin{abstract}
In this study sodium alginate (NaAlg)/poly(vinyl pyrrolidone) (PVP) blend membranes were prepared and crosslinked with $\mathrm{CaCl}_{2}(0.1$ Molarity (M)) for the separation of aqueous/dimethylformamide (DMF) mixtures. Membranes were characterized by Fourier transform infrared spectroscopy (FTIR), scanning electron microscopy (SEM) and their performance was examined by varying experimental parameters such as feed composition $(0-100 \mathrm{wt} \%)$, operating temperature $\left(30^{\circ} \mathrm{C}-50^{\circ} \mathrm{C}\right)$ and membrane thickness $(30$ - 90 micrometer $(\mu \mathrm{m})$ ). Blending NaAlg with PVP, decreased separation factor whereas increased the permeation rate as the permeation temperature was increased in Vapor Permeation (VP) and Vapor Permeation with Temperature Difference (TDVP) methods. In the TDVP method, the separation factors increased and the permeation rates decreased as the temperature of the membrane surrounding is decreased. The highest separation factor of 60 was obtained in TDVP method for $90 \mathrm{wt} \%$ DMF concentration in the feed.
\end{abstract}

Keywords: Vapor Permeation, Sodium Alginate, Dimethylformamide, Membrane, Poly(Vinyl Pyrrolidone)

\section{Introduction}

Vapor permeation and vapor permeation with temperature difference methods were proposed by Uragami and coworkers [1-2]. In these methods, membrane is in contact with the vapor of feed mixture (Figure 1). Hence, the swelling or shrinking of the membranes due to the feed mixtures can be largely prevented and consequently improvement of membrane performance may be expected. Furthermore, a temperature difference between the membrane surrounding and the feed mixture was established in the TDVP method (Figure 2).

DMF is an important solvent, it is primarily used as a solvent in the production of acrylic fibers and plastics. It is also used as a solvent in peptide coupling for pharmaceutics, in the development and production of pesticides and in the manufacture of adhesives, synthetic leathers, films and surface coatings [3]. Its separation from water is important and essential because of it is carcinogenic to human beings and other animals.

Alginic acid is a highly hydrophilic polymer used in biotechnology, pharmaceutical, and cosmetic industries.

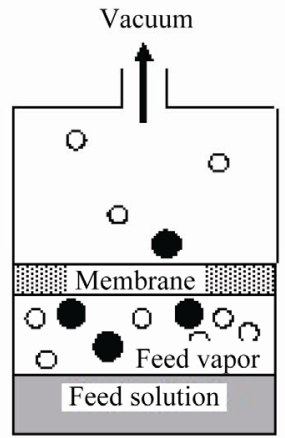

(a)

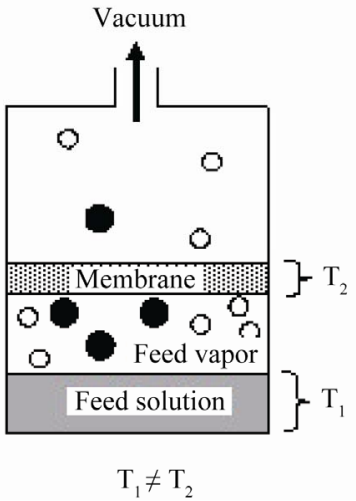

(b)
Figure 1. Schematic diagram of (a) the VP method, (b) TDVP method. 


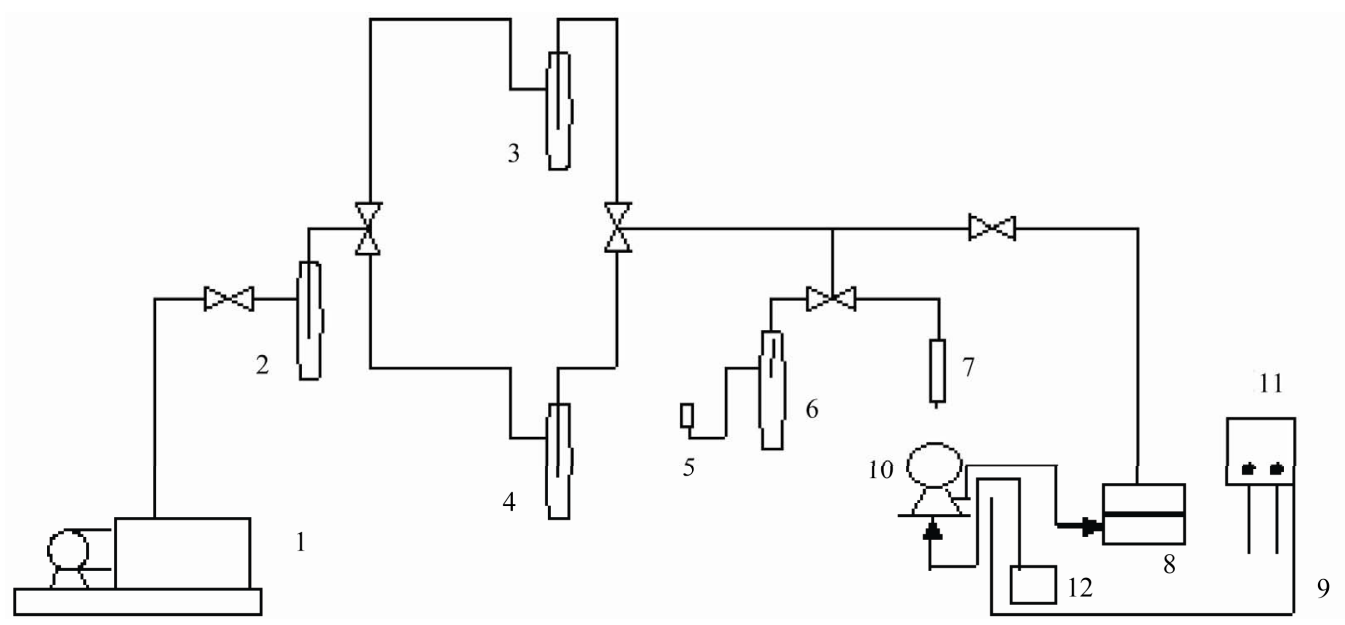

Figure 2. Schematic diagram of the vapor permeation and vapor permeation with temperature difference apparatus used in this study: 1 vacuum pump, 2-4, 6 permeation traps; 5 Mc Leod manometer; 7 vent; 8 permeation cell; 9 constant temperature water bath; 10 peristaltic pump; 11 temperature indicator; 12 feed tank.

It has widespread applications as a membrane material because of its high hydrophilicity [4-7]. Although alginic acid can hardly dissolve in commercially available solvents, its alkali metal salt form (alginate), obtained by neutralizing the acidic functional groups with strong alkalis, is well soluble in water. Thus, a membrane can be easily prepared from an alginate aqueous solution. When a highly permeable polymer material is preferred, this membrane material should be modified to have suitable combination of permeation rate and separation factor. In recent years alginic acid based membranes and their modified forms are used in VP and TDVP methods [8-10]. For this purpose, alginate and PVP semi-IPN membranes were prepared and successfully crosslinked with $\mathrm{CaCl}_{2}$ in this study (Scheme 1).

PVP is soluble in water and other polar solvents. When dry it is a light flaky powder, which readily absorbs up to $18 \%$ of its weight in atmospheric water. In solution, it has excellent wetting properties and readily forms films. The monomer is carcinogenic and is extremely toxic to aquatic life. However, the polymer PVP in its pure form is so safe that not only it is edible by humans, but also it was used as a blood plasma expander for trauma victims after the first half of $20^{\text {th }}$ century.

There are a few articles about the DMF and water mixtures in the literature [8-14]. Shah and coworkers [12] prepared hydrophilic zeolite NaA membranes for the PV separation of DMF-water mixtures. They have reported that the water flux for the DMF-water system decreases rapidly with an increase in feed DMF concentration. Aminabhavi and Naik [13] grafted poly(vinyl alcohol) (PVA) with acrylamide for the separation of water/DMF mixtures. It was found that these membranes are more selective to water than DMF. Separation factors increased with grafting, but permeation flux did not con- siderable change with grafting.

In our previous study [10] we have used NaAlg/PVP membrane for the pervaporation separation of aqueous/DMF mixtures. As a confirmation of the use of $\mathrm{NaAlg} / \mathrm{PVP}$ membranes, in this research we have aimed to investigate separation characteristics of aqueous/DMF mixtures by VP and TDVP methods.

\section{Experimental}

\subsection{Materials}

DMF $\left(\mathrm{C}_{3} \mathrm{H}_{7} \mathrm{NO}\right.$, purity; $\left.99.9 \%\right)$, calcium chloride $\left(\mathrm{CaCl}_{2}\right.$, purity; $90 \%)$ and PVP $\left(\left(\mathrm{C}_{6} \mathrm{H}_{9} \mathrm{NO}\right)_{\mathrm{n}}\right.$, purity; $\left.99.9 \%\right)$ were obtained from Merck and used as supplied. NaAlg $\left(\left(\mathrm{C}_{6} \mathrm{H}_{7} \mathrm{NaO}_{6}\right)_{\mathrm{n}}\right.$, medium viscosity) was provided from Sigma.

\subsection{Preparation of Blend Membranes}

PVP ( $8 \mathrm{wt} \%)$ and NaAlg (2 $\mathrm{wt} \%)$ were dissolved in water, mixed in different ratios $(w / w)$, stirred and then casted onto rimmed round glass dishes [10].

Solvent was evaporated at $60^{\circ} \mathrm{C}$ to form the membrane. The dried membrane was crosslinked with calcium chloride $(0.1 \mathrm{M})$ for $24 \mathrm{~h}$. The thickness of the membranes thus prepared was $70( \pm 10) \mu \mathrm{m}$. Membranes prepared in this research were used at least 10 times without any deformation during the VP and TDVP processes.

\subsection{Swelling Study of the Blend Membranes}

Dried membranes were immersed in different concentrations of DMF/water mixtures at $40^{\circ} \mathrm{C}$ for $48 \mathrm{~h}$. Then these membranes wiped with cleansing tissue to remove 

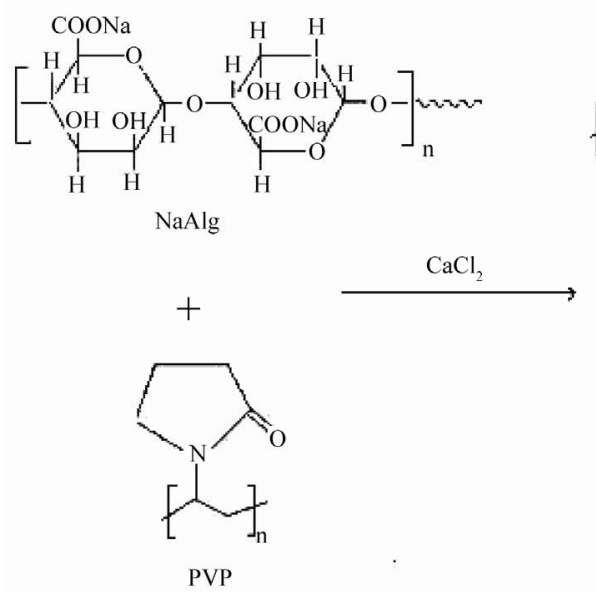
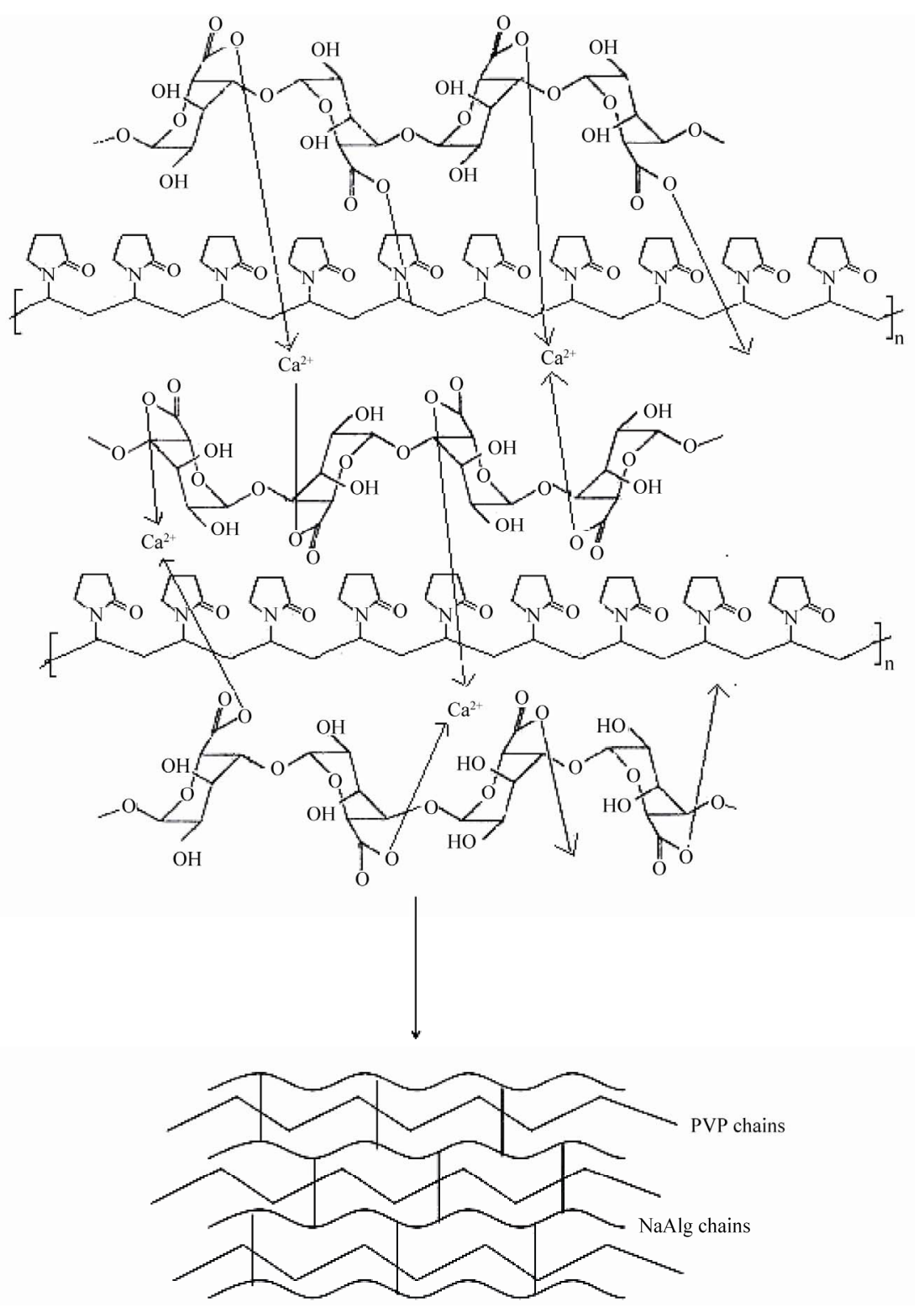

Scheme 1. Schematic representation of the polymer.

the excess solvent mixture. These samples were dried at $60{ }^{\circ} \mathrm{C}$ until a constant weight and water uptake was calculated as;

$$
\text { Water uptake }(\%)=\frac{\left(M_{S}-M_{D}\right)}{M_{D}} \times 100
$$

where $M_{S}$ is the mass of the swollen membrane in the feed solution and $M_{D}$ is the mass of the dried membrane.

\subsection{Vapor Permeation and Vapor Permeation with Temperature Difference Experiments}

In VP and TDVP methods, the capacity of permeation cell was about $150 \mathrm{~mL}$ [8]. The effective membrane area was $16.5 \mathrm{~cm}^{2}$ and pressure was kept at 0.6 mbar with a vacuum pump (Edwards). The mixture of DMF and water that was used as a feed solution placed into the lower part of the permeation cell, permeation side of the cell (upper part) was kept under vacuum. The feed mixture was circulated between the permeation cell and feed tank at constant temperature and permeate was collected in liquid nitrogen traps. In TDVP method while the temperature of the feed solution was kept constant $40^{\circ} \mathrm{C}$ temperature of the membrane surroundings $\left(0^{\circ} \mathrm{C}-50^{\circ} \mathrm{C}\right)$ was controlled by a cold medium in a permeation cell of a jacket type. Upon reaching steady state conditions permeate vapor was collected in liquid nitrogen traps and weighed. The composition of permeates was found by 
means of refractive index values with Atago DD-5 type digital refractometer. Then these indexes were translated to concentration by using a calibration curve.

Membrane performance was expressed by separation factor $(\alpha)$ and permeation rate $(J)$. The separation factor was defined as follows [15]:

$$
\alpha_{\text {sep.W/DMF }}=\frac{P_{W} / P_{D M F}}{F_{W} / F_{D M F}}
$$

where $P_{W}$ and $P_{D M F}, F_{W}$ and $F_{D M F}$ and are the mass fractions of water and DMF components in the permeate and feed vapor (measured by isoteniscope method) respectively. The permeation rate was calculated using Equation 3 .

$$
J=\frac{W}{A \cdot t}
$$

where $W$ is the mass of permeate $(\mathrm{kg}), \mathrm{A}$ is membrane surface area $\left(\mathrm{m}^{2}\right), \mathrm{t}$ is the experiment time $(\mathrm{h})$.

\section{Results and Dicussion}

\subsection{Blend Ratio Selection and Membrane Characterization}

In our previous study (10) we have studied NaAlg/PVP blend ratios of 100/0, 95/5, 90/10, 85/15, 80/20, 75/25 (w/w) for $20 \mathrm{wt} \% \mathrm{DMF} /$ water mixtures at $40^{\circ} \mathrm{C}$ and decided to use $75 / 25$ ratio due to its acceptable flux and separation factor. For this reason in this study we have used this ratio for the membrane preparation. It was found in the previous study that, the permeation rate increases whereas separation factor decreases as the PVP content of the membrane increases [16-18]. In this study, the results were supported by the crosslink density and molecular mass between crosslinks $\left(M_{C}\right)$ (Table 1).

$M_{C}$ of the polymer was determined by using FloryRehner Equation [19] as given below:

$$
M_{C}=-\delta_{p} V_{S} \phi^{1 / 3}\left[\ln (1-\phi)+\varphi+\chi \phi^{2}\right]^{-1}
$$

$\phi$ is the volume fraction of the polymer in the swollen state and can be calculated as:

Table 1. Molecular mass between crosslinks $\left(M_{C}\right)$ values and crosslink density $(\delta x)$ of the NaAlg/PVP blend membranes.

\begin{tabular}{ccc}
\hline $\mathrm{NaAlg} / \mathrm{PVP}(\mathrm{w} / \mathrm{w})$ & $\delta_{x}\left(\mathrm{~mol} / \mathrm{cm}^{3}\right) \times 10^{-4}$ & $M_{C}(\mathrm{~g} / \mathrm{mol}) \times 10^{3}$ \\
\hline $100 / 0$ & 10.52 & 0.565 \\
$95 / 5$ & 9.81 & 0.670 \\
$90 / 10$ & 8.23 & 0.711 \\
$85 / 15$ & 7.01 & 0.956 \\
$80 / 20$ & 6.94 & 1.143 \\
$75 / 25$ & 5.30 & 1.680 \\
\hline
\end{tabular}

$$
\phi=\left[1+\frac{\delta_{P}}{\delta_{S}}\left(\frac{M_{a}}{M_{b}}\right)-\frac{\delta_{P}}{\delta_{S}}\right]^{-1}
$$

where $\delta_{P}$ and $\delta_{S}$ are the densities of the polymer and solvent, respectively. $M_{a}$ and $M_{b}$ are the mass of the polymer before and after swelling, respectively. $V_{s}$ is the molar volume fraction of the polymer in the swollen state.

Interaction parameter $\chi$ can be calculated from following equation.

$$
\begin{aligned}
\chi= & {\left[\phi(1-\phi)^{-1}+N \ln (1-\phi)+N \phi\right] } \\
& \cdot\left[2 \phi-\phi^{2} N-\phi^{2} T^{-1} \cdot(\partial \phi / \partial T)^{-1}\right]^{-1}
\end{aligned}
$$

where $N=\left(\phi^{2 / 3} / 3-2 / 3\right)\left(\phi^{1 / 3}-2 \phi / 3\right)^{-1}$ and temperature is taken as Kelvin.

For the NaAlg/PVP membrane, the $M_{C}$ value was found to be 1680 .

Finally crosslink density, $\delta_{x}$;

$$
\delta_{x}=\delta_{p} / M_{c}
$$

In our study the crosslink density of NaAlg/PVP $(75 / 25, \mathrm{w} / \mathrm{w})$ membrane was found as $5.30 \times 10^{-4}$ $\mathrm{mol} / \mathrm{cm}^{3}$ taking the $\chi$ (aqueous/DMF) as 0.7238 .

We have studied with 75/25 (NaAlg/PVP, w/w) ratio in the rest of the study due to acceptable flux and separation factor. The prepared membrane was characterized with Fourier transform infrared spectroscopy (Figure 3) and scanning electron microscopy (Figure 4).

Crosslinked membrane was scanned with Mattson 1000 Fourier Transfer Infrared Spectroscopy (FTIR) (Figure 3). In the FTIR spectrum of NaAlg/PVP and $\mathrm{NaAlg}$, the peak at $3000-3500 \mathrm{~cm}^{-1}$ area presences the stretching vibration of $-\mathrm{OH}$ band. In the FTIR spectrum of $\mathrm{NaAlg} / \mathrm{PVP}$ these stretching vibrations appear as a wider band than the spectrum of NaAlg. This peak appear at $3445 \mathrm{~cm}^{-1}$ in the spectrum of PVP. The peak at $1625 \mathrm{~cm}^{-1}$ in the spectrum of $\mathrm{NaAlg}$ is due to the stretching band of $\mathrm{C}=\mathrm{O}$. The spectrum of PVP appears strong absorption band at $1640 \mathrm{~cm}^{-1}$, due to the presence of the $\mathrm{C}=\mathrm{C}-\mathrm{N}$ group. In the FTIR spectrum of $\mathrm{NaAlg} / \mathrm{PVP}$, these bands were seen together. The spectrums of PVP, NaAlg and NaAlg/PVP appear stretching bands of C-H group at $2964 \mathrm{~cm}^{-1}, 2946 \mathrm{~cm}^{-1}$ and 2954 $\mathrm{cm}^{-1}$, respectively.

The morphology of the NaAlg and NaAlg/PVP membranes was observed using Scanning Electron Microscopy (SEM, JEOL JSM-6400) (Figures 4(a) and 4(b)). It was seen from the SEM results that the NaAlg membrane surface (Figure 4(a)) had a smoother appearance than the blend membrane [10]. 


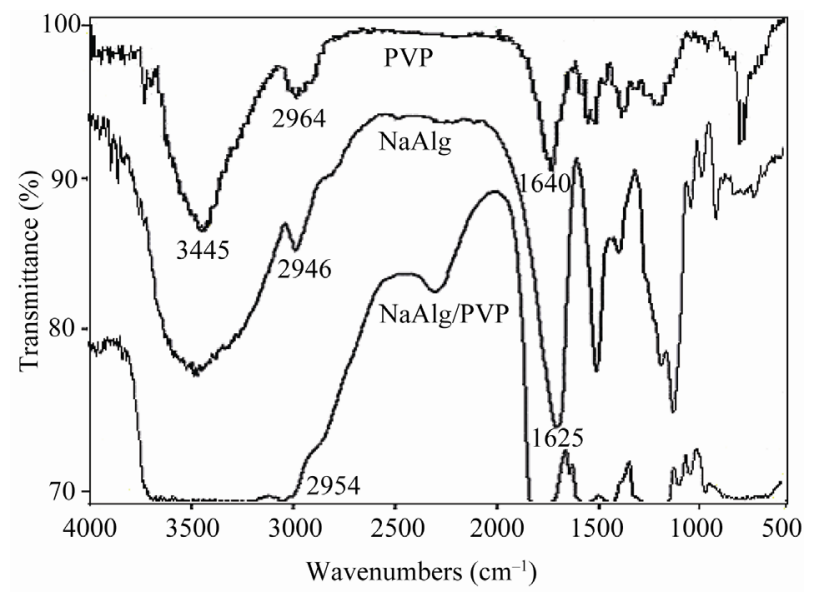

Figure 3. IR spectra of NaAlg/PVP, PVP and NaAlg membranes.

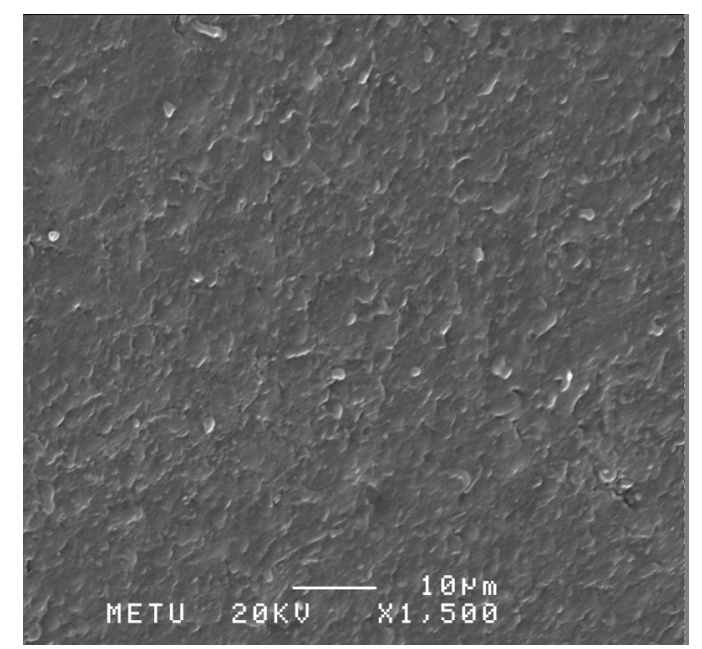

(a)

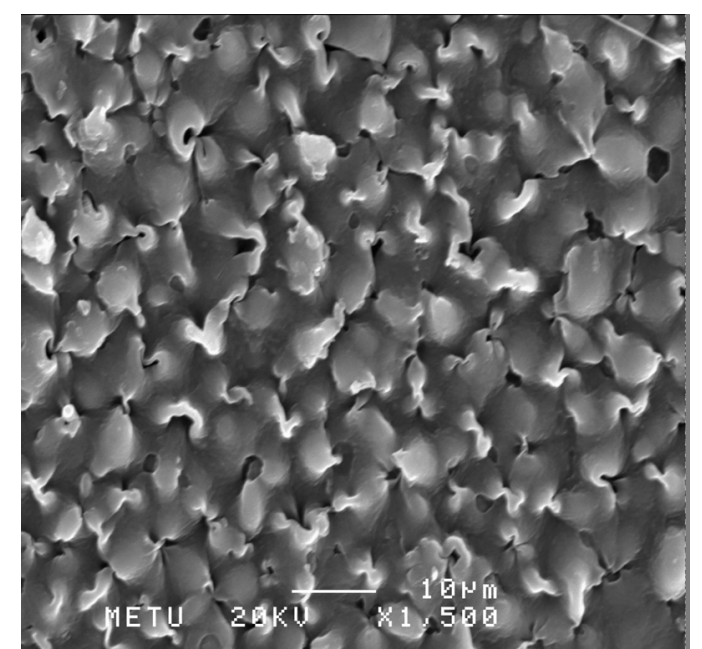

(b)

Figure 4. (a) Scanning electron microscopic picture of NaAlg membrane; (b) Scanning electron microscopic picture of NaAlg/PVP membrane.

\subsection{Effect of Temperature in VP}

The effect of operating temperature on the permeation rate and separation factor was studied for the NaAlg/PVP semi-IPN membrane using $20 \mathrm{wt} \%$ dimethylformamide solutions. Results were shown in Figure 5. Permeation rate increased whereas the separation factors decreased as the operating temperature increased. The temperature increases membrane becomes more swollen and both DMF and water molecules diffuse easily through the membrane. As a result, the permeation rate increases whereas the separation factor decreases with increasing temperature. Similar results were reported in the literature [20-23].

Sommer and Melin [22] studied influence of operation parameters on the separation of mixtures by pervaporation and vapor permeation with silica membranes. They have reported that increase in temperature improved flux rates for alcohol/water mixtures.

\subsection{Effect of Feed Composition in VP}

Figure 6 illustrates the permeation performance of semi-IPN membranes in VP at $40^{\circ} \mathrm{C}$. As can be seen from the figure, the best separation factors were obtained at high feed compositions. As the amount of water in the feed vapor increases membrane material becomes more swollen (Figure 7) and DMF molecules that have larger moleculer size than that of water molecules diffuse easily through the swollen membrane. As a result, the permeation rate increases whereas the separation factor decreases with increasing water content. Similar results were reported in the literature $[8,12]$.

\subsection{Effect of the Membrane Surrounding Temperature in TDVP}

The effect of temperature of the membrane surroundings

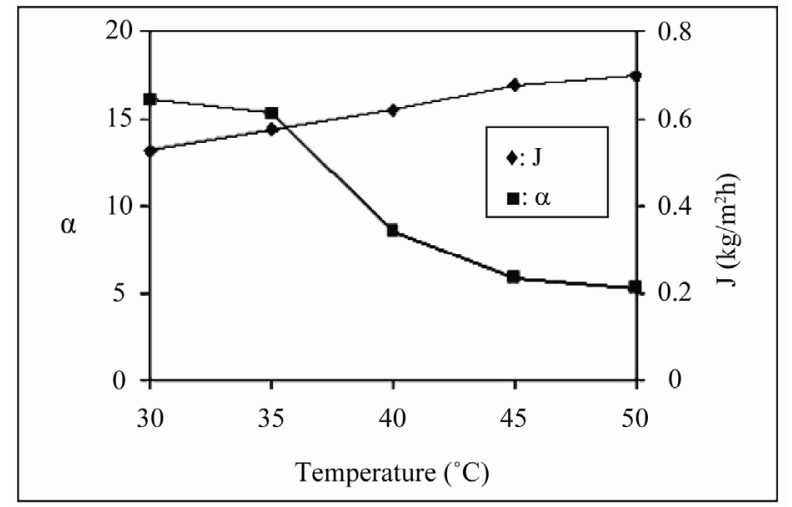

Figure 5. Change in the permeation rate and the separation factor with the temperature in VP. 


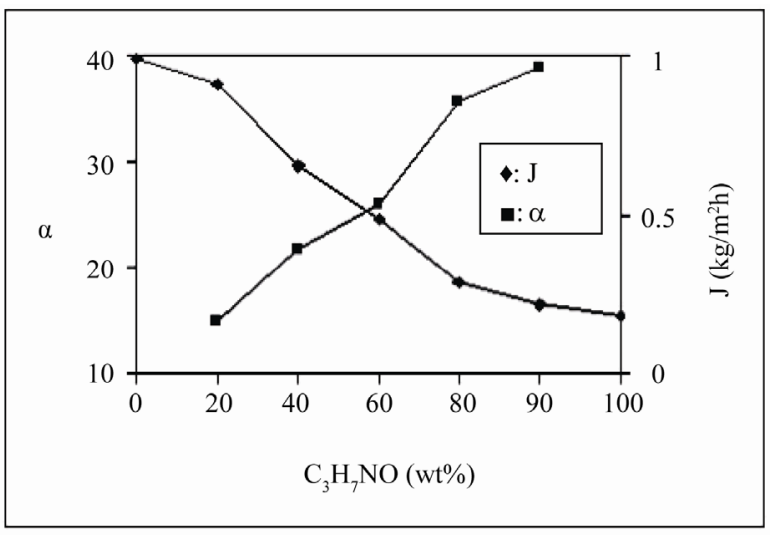

Figure 6. Effect of the feed composition in VP. The permeation conditions; membrane thickness: $70 \mu \mathrm{m}$, operating temperature: $40^{\circ} \mathrm{C}$, pressure: 0.6 mbar.

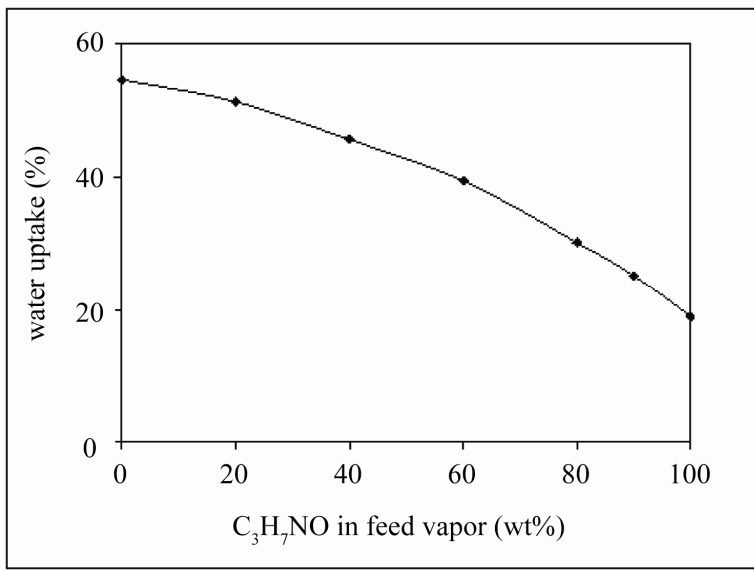

Figure 7. Change in the water uptake with the feed composition in VP.

on the permeation rate and the separation factor in TDVP was studied and results were shown in Figure 8. In the study the temperature of the feed solution was kept constant at $40^{\circ} \mathrm{C}$ and the temperature of the membrane surrounding was changed in the range of $0^{\circ} \mathrm{C}-50^{\circ} \mathrm{C}$. Increase in the temperature of the membrane surroundings increased the permeation rate and decreased the separation factor. Similar results were reported in the literature [8].

Kondolot Solak and Şanlı [8] studied the separation characteristics of dimethylformamide/water mixtures through alginate membranes by pervaporation, vapor permeation and vapor permeation with temperature difference methods. They have observed that the permeation rate increased with the increase in temperature of the membrane surroundings so the separation factor decreased.

The comparison of both methods was shown in Figures 9 and 10. As it is from the figures that the highest separation factors were obtained in TDEV method. This may

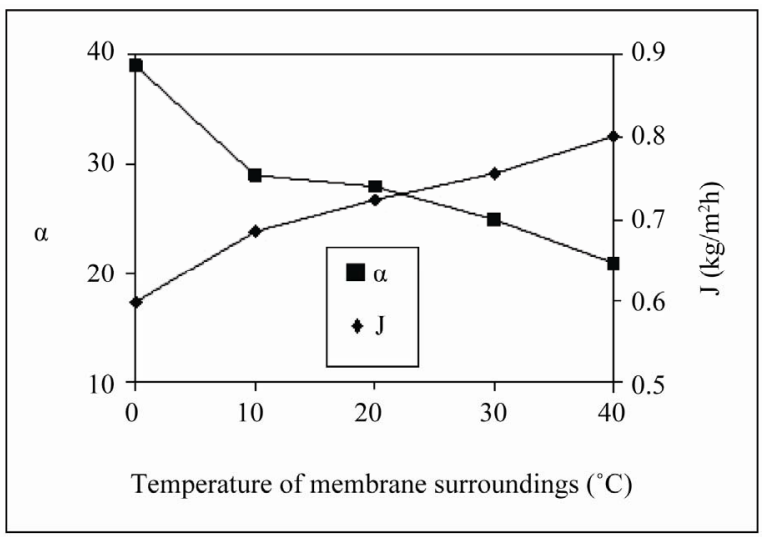

Figure 8. Effect of the temperature of the membrane surroundings on the permeation rate and separation factor. The permeation conditions; membrane thickness: $70 \mu \mathrm{m}$, temperature of the feed solution: $40^{\circ} \mathrm{C}$, pressure: $0.6 \mathrm{mbar}$.

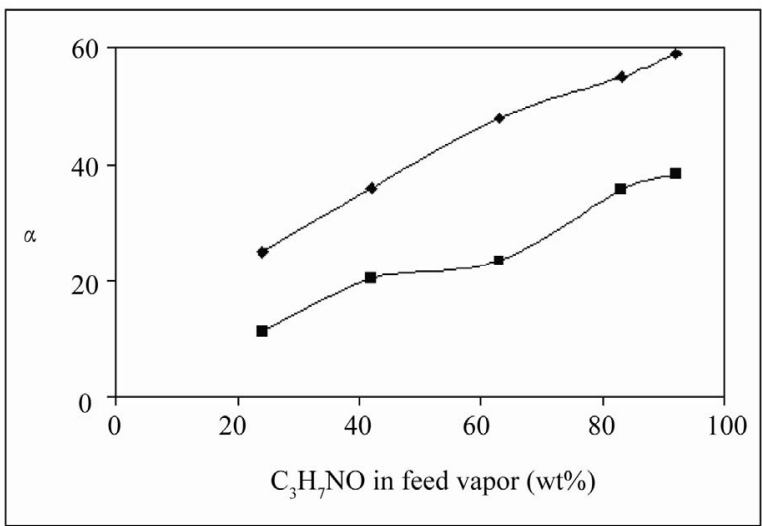

Figure 9. Change in the separation factor in VP ( $\square)$ and TDVP ( ) methods. The permeation conditions; membrane thickness: $70 \mu \mathrm{m}$, operating temperature: $40^{\circ} \mathrm{C}$, pressure: 0.6 mbar, membrane surrounding temperature: $10^{\circ} \mathrm{C}$.

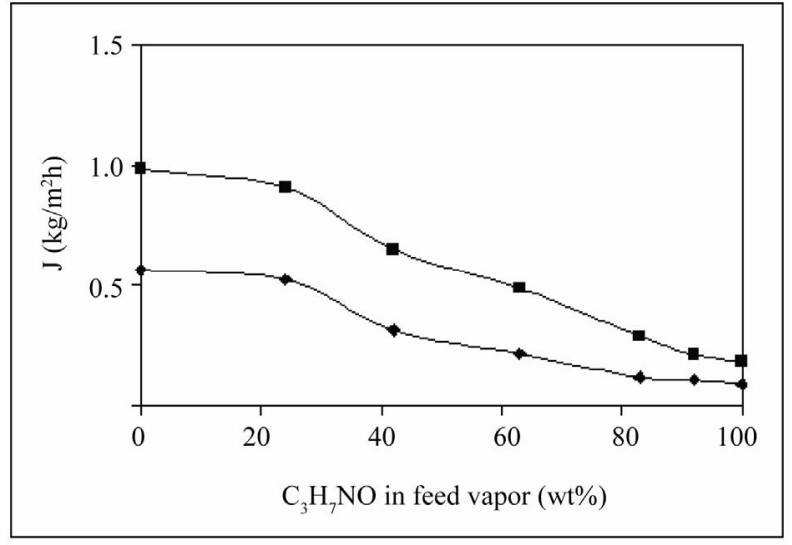

Figure 10. Change in the permeation rate in VP (a) and TDVP ( $\bullet$ methods. The permeation conditions were as follows; membrane thickness: $70 \mu \mathrm{m}$, operating temperature: $40^{\circ} \mathrm{C}$, pressure: $0.6 \mathrm{mbar}$, membrane surrounding temperature: $10^{\circ} \mathrm{C}$. 
be attributed to the temperature difference between the feed mixture and the membrane surrounding. When the dimethylformamide and water molecules were vaporized, these vaporized molecules came close the membrane surrounding kept at a lower temperature, the DMF molecules were liable to be aggregated more than the water molecules (the freezing point of DMF $\left(-61^{\circ} \mathrm{C}\right)$ is lower than that of water $\left.\left(0^{\circ} \mathrm{C}\right)\right)$. This aggregation of DMF was responsible for the increase of separation factor of water.

\section{Conclusions}

NaAlg/PVP blend membrane have been prepared and used in the separation of aqueous/DMF mixtures by vapor permeation and vapor permeation with temperature difference methods. It was shown experimentally that membranes could be used to separate aqueous/DMF mixtures with acceptable permeation rates and separation factors. The effects of feed composition, permeation temperature and membrane surrounding temperature on the permeation rate and the separation factor were investtigated. Increase in the operating temperature in VP and TDVP methods increased the permeation rate whereas decreased the separation factor. Permeation rate decreased whereas separation factor increased as the DMF content of the feed increased in both methods. The highest separation factor (60) was found in TDVP method whereas highest permeation rate $\left(0.986 \mathrm{~kg} / \mathrm{m}^{2} \mathrm{~h}\right)$ was observed in VP method.

\section{Acknowledgements}

The authors are grateful to Gazi University Research Fund for the support of this study.

\section{References}

[1] T. Uragami and K. Takigawa, "Permeation and Separation Characteristics of Ethanol-Water Mixtures through Chitosan Derivative Membranes by Pervaporation and Evapomeation," Polymer, Vol. 31, No. 4, 1990, pp. 668672. doi:10.1016/0032-3861(90)90287-9

[2] T. Uragami, S. Kato and T. Miyata, "Structure of N-alkyl Chitosan Membranes on Water-Permselectivity for Aqueous Ethanol Solutions," Journal of Membrane Science, Vol. 124, No. 2, 1997, pp. 203-211. doi:10.1016/S0376-7388(96)00238-4

[3] C. A. Redich, W. S. Beckett, J. Sparer, K. W. Barwich, C. A. Riely, H. Miller, S. L. Sigal, S. L. Shalat and M. R. Cullen, "Liver Disease Associated with Occupational Exposure to the Solvent Dimethylformamide," Annals of Internal Medicine, Vol. 108, No. 5, 1998, pp. 680-686.

[4] X. P. Wang, "Preparation of Crosslinked Alginate Composite Membrane for Dehydration of Ethanol-Water Mix- tures", Journal of Applied Polymer Science, Vol. 77, No. 14, 2000, pp. 3054-3061. doi:10.1002/1097-4628(20000929)77:14<3054::AID-AP P50>3.0.CO;2-L

[5] C. K. Yeom and K. H. Lee, "Characterization of Sodium Alginate and Poly (Vinyl Alcohol) Blend Membranes in Pervaporation Separation," Journal of Applied Polymer Science, Vol. 67, No. 5, 1998, pp. 949-959.

doi:10.1002/(SICI)1097-4628(19980131)67:5<949::AIDAPP20>3.0.CO;2-H

[6] Y. Shi, X. Wang, G. Chen, G. Golemme and S. Zhang, "Preparation and Characterization of High-Performance Dehydrating Pervaporation Alginate Membranes," Journal of Applied Polymer Science, Vol. 68, No. 6, 1998, pp. 959-968.

doi:10.1002/(SICI)1097-4628(19980509)68:6<959::AIDAPP9>3.0.CO;2-G

[7] C. K. Yeom and K. H. Lee, "Characterization of Sodium Alginate Membrane Crosslinked with Glutaraldehyde in Pervaporation Separation", Journal of Applied Polymer Science, Vol. 67, No. 2, 1998, pp. 209-219. doi:10.1002/(SICI) 1097-4628(19980110)67:2<209::AIDAPP3>3.0.CO;2-Y

[8] E. Kondolot Solak and O. Şanl1, "Separation Characteristics of Dimethylformamide/Water Mixtures through Alginate Membranes by Pervaporation, Vapor Permeation and Vapor Permeation with Temperature Difference Methods," Separation Science and Technology, Vol. 41, 2006, pp. 627-646. doi:10.1080/01496390500526789

[9] E. Kondolot Solak and O. Şanl1, "Separation Characteristics of Dimethylformamide/Water Mixtures Using Sodium Alginate-g-N-vinyl-2-Pyrrolidone Membranes by Pervaporation Method," Chemical Engineering and Prosessing, Vol. 47, No. 4, 2008, pp. 633-641.

doi:10.1016/j.cep.2006.12.001

[10] E. Kondolot Solak, G. Asman, P. Çamurlu and O. Şanlı, "Sorption, Diffusion, and Pervaporation Characteristics of Dimethylformamide/Water Mixtures Using Sodium Alginate/Polyvinyl Pyrrolidone Blend Membranes," $\mathrm{Va}$ cuum, Vol. 82, No. 6, 2008, pp. 579-587. doi:10.1016/j.vacuum.2007.08.012

[11] D. A. Devi, B. Smitha, S. Sridhar and T. M. Aminabhavi, "Pervaporation Separation of Dimethylformamide/Water Mixtures through Poly(Vinyl Alcohol)/Poly(Acrylic Acid) Blend Membranes," Separation and Purification Technology, Vol. 51, No. 1, 2006, pp. 104-111. doi:10.1016/j.seppur.2006.01.006

[12] D. Shah, K. Kissick, A. Ghorpade, R. Hannah amd D. Bhattacharyya, "Pervaporation of Alcohol-Water and Dimethylformamide-Water Mixtures Using Hydrophilic Zeolite NaA Membranes: Mechanisms and Experimental Results," Journal of Membrane Science, Vol. 179, No. 1-2, 2000, pp. 185-205. doi:10.1016/S0376-7388(00)00515-9

[13] T. M. Aminabhavi and H. G. Naik, "Pervaporation Separation of Water/Dimethylformamide Mixtures Using Poly(Vinyl Alcohol)-g-polyacrylamide Copolymeric Membranes," Journal of Applied Polymer Science, Vol. 83, No. 2, 2002, pp. 273-282. doi:10.1002/app.2242

[14] M. D. Kurkuri and T. M. Aminabhavi, "Polyacryloni- 
Trile-g-Poly(Vinyl Alcohol) Membranes for the Pervaporation Separation of Dimethyl Formamide and Water Mixtures," Journal of Applied Polymer Science, Vol. 91, No. 6, 2004, pp. 4091-4097. doi:10.1002/app.13640

[15] G. Asman and O. Şanl, "Characteristics of Permeation and Separation for Acetic Acid-Water Mixtures Through Poly(Vinyl Alcohol) Membranes Modified with Poly(Acrylic Acid)," Separation Science and Technology, Vol. 38, No. 9, 2003, pp. 1963-1980. doi:10.1081/SS-120020129

[16] H. Wu, X. Fang, X. Zhang, Z. Jiang, B. Li and X. Ma, "Cellulose Acetate-Poly(N-Vinyl-2-pyrrolidone) Blend Membrane for Pervaporation Separation of Methanol/ MTBE Mixtures," Separation and Purification Techno- logy, Vol. 64, No. 2, 2008, pp. 183-191. doi:10.1016/j.seppur.2008.09.013

[17] X. H. Zhang, Q. L. Liu, Y. Xiong, A. Zhu, M. Y. Chen and Q. G. Zhang, "Pervaporation Dehydration of Ethyl Acetate/Ethanol/Water Azeotrope Using Chitosan/Poly(Vinyl Pyrrolidone) Blend Membranes," Journal of Membrane Science, Vol. 327, No. 1-2, 2009, pp. 274-280. doi:10.1016/j.memsci.2008.11.034

[18] J. Lu, Q. Nguyen, L. Zhou, B. Xu and Z. Ping, "Study of the Role of Water in the Transport of Water and THF through Hydrophilic Membranes by Pervaporation," Journal of Membrane Science, Vol. 226, No. 1-2, 2003, pp. 135-143. doi:10.1016/j.memsci.2003.08.016
[19] P. J. Flory, "Principles of Polymer Chemistry," Cornell University, Ithaca, New York, 1953.

[20] D. A. Devi, B. Smitha, S. Sridhar and T. M. Aminabhavi, "Pervaporation Separation of Dimethylformamide/Water Mixtures through Poly(Vinyl Alcohol)/Poly(Acrylic Acid) Blend Membranes," Separation and Purufication Technology, Vol. 51, No. 1, 2006, pp. 104-111. doi:10.1016/j.seppur.2006.01.006

[21] S. Sommer and T. Melin, "Influence of Operation Parameters on the Separation of Mixtures by Pervaporation and Vapor Permeation with Inorganic Membranes. Part 2: Purely Organic Systems," Chemical Engineering and Science, Vol. 60, No. 16, 2005, pp. 4525-4533. doi:10.1016/j.ces.2005.02.070

[22] S. Sommer and T. Melin, "Influence of Operation Parameters on the Separation of Mixtures by Pervaporation and Vapor Permeation with Inorganic Membranes. Part 1: Dehydration of Solvents," Chemical Engineering and Science, Vol. 60, No. 16, 2005, pp. 4509-4523. doi:10.1016/j.ces.2005.02.059

[23] J. E. Elshof, C. R. Abadal, J. Sekulic, S. R. Chrowdhury and D. H. A. Blank, "Transport Mechanisms of Water and Organic Solvents through Microporous Silica in the Pervaporation of Binary Liquids," Microporous Mesoporous Materials, Vol. 65, No. 2-3, 2003, pp. 197-208. doi:10.1016/j.micromeso.2003.08.010 